\title{
Comparison of head impact exposure in practice drills among multiple youth football teams
}

\author{
Mireille E. Kelley, MS, ${ }^{1,2}$ Mark A. Espeland, PhD, ${ }^{3}$ William C. Flood, BS, ${ }^{1,2}$ \\ Alexander K. Powers, MD, ${ }^{4}$ Christopher T. Whitlow, MD, PhD, MHA, ${ }^{1,5,6}$ Joseph A. Maldjian, MD, ${ }^{7}$ \\ Joel D. Stitzel, PhD, ${ }^{1,2}$ and Jillian E. Urban, PhD, MPH ${ }^{1,2}$ \\ 1Virginia Tech-Wake Forest University School of Biomedical Engineering and Sciences; Departments of ${ }^{2 B}$ Biomedical \\ Engineering, ${ }^{3}$ Biostatistical Sciences, ${ }^{4}$ Neurosurgery, and ${ }^{5}$ Radiology (Neuroradiology); and ${ }^{6} \mathrm{Clinical}$ and Translational Sciences \\ Institute, Wake Forest School of Medicine, Winston-Salem, North Carolina; and 'Department of Radiology, University of Texas \\ Southwestern, Dallas, Texas
}

OBJECTIVE Limiting contact in football practice can reduce the number of head impacts a player receives, but further research is needed to inform the modification of optimal drills that mitigate head impact exposure (HIE) while the player develops the skills needed to safely play the game. This study aimed to compare HIE in practice drills among 6 youth football teams and to evaluate the effect of a team on HIE.

METHODS On-field head impact data were collected from athletes (ages 10-13 years) playing on 6 local youth football teams (teams A-F) during all practices using the Head Impact Telemetry System. Video was recorded and analyzed to verify and assign impacts to a specific drill. Drills were identified as follows: dummy/sled tackling, half install, install, install walk through, multiplayer tackle, Oklahoma, one-on-one, open field tackling, other, passing, position skill work, scrimmage, special teams, tackling drill stations, and technique. HIE was quantified in terms of impacts per player per minute (ppm) and peak linear and rotational head acceleration. Generalized linear models were used to assess differences in head impact magnitude and frequency among drills as well as among teams within the most common drills.

RESULTS Among 67 athlete-seasons, a total of 14,718 impacts during contact practices were collected and evaluated in this study. Among all 6 teams, the mean linear $(p<0.0001)$ and rotational $(p<0.0001)$ acceleration varied significantly among all drills. Open field tackling had significantly $(p<0.001)$ higher mean linear acceleration than all other drills. Multiplayer tackle had the highest mean impact rate $(0.35 \mathrm{ppm})$. Significant variations in linear acceleration and impact rate were observed among teams within specific drills. Team $A$ had the highest mean linear acceleration in install, oneon-one, and open field tackling and the highest mean impact rate in Oklahoma and position skill work. Although team $\mathrm{A}$ spent the greatest proportion of their practice on minimal- or no-player versus player contact drills (27\%) compared to other teams, they had the highest median $(20.2 \mathrm{~g})$ and 95 th percentile $(56.4 \mathrm{~g})$ linear acceleration in practice.

CONCLUSIONS Full-speed tackling and blocking drills resulted in the highest HIE. Reducing time spent on contact drills relative to minimal or no contact drills may not lower overall HIE. Instead, interventions such as reducing the speed of players engaged in contact, correcting tackling technique, and progressing to contact may reduce HIE more effectively.

https://thejns.org/doi/abs/10.3171/2018.9.PEDS18314

KEYWORDS head impacts; biomechanics; pediatrics; head acceleration; football; injury; trauma

$\mathrm{T}$ HERE are numerous benefits to adolescents participating in sports, such as improved physical and mental health, psychosocial development, and selfconfidence, ${ }^{17,20,42,44}$ however, there are also injury risks, especially in full-contact sports, such as football. ${ }^{3,7,23,35}$ The high injury and concussion rates in football compared to other sports are of increasing concern. ${ }^{1,26}$ Repetitive concussive and subconcussive head impacts (i.e., those that do not result in the signs and symptoms of a clinically diagnosed concussion) in contact sports may also be linked

ABBREVIATIONS HIE = head impact exposure; HIT = Head Impact Telemetry; ppm = impacts per player per minute.

SUBMITTED May 25, 2018. ACCEPTED September 26, 2018.

INCLUDE WHEN CITING Published online December 21, 2018; DOI: 10.3171/2018.9.PEDS18314. 
TABLE 1. Age and weight requirements for each team included in the study

\begin{tabular}{ccc}
\hline Teams & Age Requirements (yrs) & Max Weight* $\left.{ }^{*} \mathrm{lbs}\right)$ \\
\hline A \& B & $\leq 10 \mathrm{yrs}, 11$ & 124 ( $\leq 10 \mathrm{yrs}), 104$ (11 yrs) \\
\hline C \& D & $\leq 11 \mathrm{yrs}, 12$ & $139(\leq 11 \mathrm{yrs}), 119(12 \mathrm{yrs})$ \\
\hline E \& F & $\leq 12 \mathrm{yrs}, 13$ & $159(\leq 12 \mathrm{yrs}), 139(13 \mathrm{yrs})$ \\
\hline
\end{tabular}

* Five pounds are allowed at precompetition weigh-in for all equipment.

to later-life neurodegenerative disease..$^{31,32}$ Additionally, studies have shown significant positive correlations between subconcussive head impact exposure (HIE) metrics and brain imaging and cognitive measures in youth, high school, and collegiate football athletes, even after one season of play and in the absence of a clinically diagnosed concussion. , $16,30,41$ However, a tolerable "threshold" for the number and severity of head impacts an athlete is exposed to over a season or a lifetime is not yet known. While the relationship between repetitive head impacts in football and short- and long-term effects is not fully understood, it is imperative to reduce exposure to head impacts in football to protect athletes from injury and improve safety of the sport. $33,37,38,40$

Collecting on-field head impact data from collegiate, high school, and youth football athletes has improved our understanding of head impact biomechanics in football. $5,14,22,43$ With approximately $70 \%$ of athletes playing youth football, there has been a greater focus recently on studying HIE in this population. Studies have shown that youth athletes experience high-magnitude head impacts (> $80 \mathrm{~g}$ ) in practices and games, similar to their older counterparts., ${ }^{9,222}$ Youth football spans the ages of 5 to 13 years, and teams are often defined by age and/or weight. A recent study found that younger football players (ages 10-11) are more frequently exposed to high-magnitude impacts in practices, whereas older youth football players (ages 12-13) are exposed to more high-magnitude impacts in games; ${ }^{22}$ however, the majority of head impacts occur in practice rather than games for most athletes. ${ }^{12,15,22}$

On-field head impact data have been used to inform evidence-based rule changes to reduce HIE and evaluate the effectiveness of rule changes. ${ }^{6,12,15}$ Prior efforts to reduce HIE have primarily focused on reducing the amount of time allowed for contact in practice. ${ }^{6,12} \mathrm{Cobb}$ et al. found that athletes on a youth football team that implemented Pop Warner's 2012 rule change to limit contact in practice had $37 \%-46 \%$ fewer impacts than athletes on teams that did not have restrictions to contact in practice. ${ }^{12}$ Similarly, limiting contact to no more than 2 collision practice days in any week in a high school football team resulted in an average $42 \%$ reduction in the number of head impacts. ${ }^{6}$ Alternatively, some coaches have implemented helmetless tackling in practice. Early results show that athletes participating in a helmet-less tackling program had $30 \%$ fewer impacts per athletic exposure than athletes not participating in the program. ${ }^{40}$

Studies have also shown that teaching and enforcing proper tackling technique can reduce the number of head impacts and mitigate injury risk. $9,11,12,24,25$ In particular, the Head's Up Football program, which educates coaches on proper tackling technique and injury prevention, may help reduce the number of injuries and impacts in practice. ${ }^{24,25}$ Additionally, studies of tackling technique in rugby have shown that higher criterion-specific tackle technique scores were associated with a non-injury outcome, suggesting that performing well in tackling scenarios may reduce the risk of injury. ${ }^{8,19}$ Therefore, it may be beneficial to introduce contact and teach safe tackling technique in practice to prepare athletes for these scenarios in games. Quantifying HIE in practice drills and understanding the context in which contact occurs can inform modifications to practice structure and drill setup, while still teaching the tackling skills needed to safely play the game. Prior studies have shown that there is significant variability in HIE among drills and that full-speed tackling drills result in the highest head impact severity ${ }^{10,21}$ However, past studies of HIE in practice drills were limited to single-season evaluations and a narrow age range; therefore, the objective of the present study was to use biomechanical data and video analysis to evaluate HIE in practice drills among 6 youth football teams and to determine the effect of individual teams on HIE in drills.

\section{Methods}

On-field head impact data were collected from athletes participating in a local youth football league over 2 years. The study protocol was approved by the Wake Forest School of Medicine Institutional Review Board, and participant assent and parental consent were properly acquired for participation in the study. Athletes participating on one of 6 teams, teams A-F (teams A, C, and E in 2015 and teams B, D, and F in 2016), were included in the study. The athletes were placed on teams based on the national governing organization's age and weight requirements (Table 1). Participation in the study was voluntary. Athletes also had to properly fit into a Riddell Speed or Revolution Youth medium-size or larger helmet to be included in the study.

The Riddell helmets worn by study participants were instrumented with the Head Impact Telemetry (HIT) System MxEncoders that mount within the existing padding of the helmet. The MxEncoders include an array of 6 spring-mounted, single-axis accelerometers, a telemetry unit, data storage device, and battery pack. The accelerometers are spring-mounted to allow the encoder to remain in contact with the head throughout the duration of a head impact, ensuring measurement of head acceleration, not helmet acceleration. ${ }^{29}$ The data-processing algorithm and data-collection methodology used in this study were previously published. ${ }^{13,22}$ The HIT System has been described in the literature and has been found to reliably measure HIE. ${ }^{4,18,29}$

Head impact data were collected and video was time synched with the HIT System to record on-field activities during all preseason, regular season, and playoff practices. Video analysis was performed to verify the times that the athletes were helmeted and to identify the start and stop time of each drill. The start of the drill was when the coaches began instruction and drill setup. The end of the drill was when contact ended and the players broke from 
TABLE 2. Description of setup and purpose of each drill classification

\begin{tabular}{|c|c|c|}
\hline Drill Name & Description & Purpose \\
\hline Dummy/sled tackling & Players tackle/block a dummy or sled & Reinforce wrapping while tackling \& improve form for blocking \\
\hline Half install & Offense or defense run through game plays \& strategy & $\begin{array}{l}\text { Practice positioning \& strategy for running, passing, \& defensive plays } \\
\text { in games w/o opposing line }\end{array}$ \\
\hline Install & Intrateam scrimmage $w /$ both offense \& defense & Intrateam practice of game strategies in a gamelike situation \\
\hline Install walk through* & $\begin{array}{l}\text { Team sets up in game formation \& coach instructs \& } \\
\text { walks team through game plays }\end{array}$ & Learn about game plays \& strategy \\
\hline Multiplayer tackle & 1 defender vs 2 or 3 blockers & Improve blocking \& tackling form/technique \& improve footwork \\
\hline Oklahoma & $\begin{array}{l}\text { Tackling drill w/ tackler, blocker(s), \& ball carrier in a } \\
\text { confined space }\end{array}$ & $\begin{array}{l}\text { Simulate game speed while working to improve blocking, running, \& } \\
\text { tackling technique }\end{array}$ \\
\hline One-on-one & $\begin{array}{l}1 \text { vs } 1 \text { tackling \& blocking drill w/ the } 2 \text { athletes starting } \\
<3 \text { yds apart } \dagger\end{array}$ & Improve one-on-one tackling/blocking form \& technique \\
\hline Open field tackling & $\begin{array}{l}1 \text { vs } 1 \text { tackling drill } w / \text { the } 2 \text { athletes starting }>3 \text { yds } \\
\text { apart† }\end{array}$ & Improve form \& technique for tackling in full-speed gamelike situations \\
\hline Other* & Drills that could not be classified & Purpose varied \\
\hline Passing & $\begin{array}{l}\text { Players throw \& catch passes either w/ or w/o a } \\
\text { defender }\end{array}$ & $\begin{array}{l}\text { Improve passing/catching skills, hand-eye coordination, \& pass cover- } \\
\text { age skills }\end{array}$ \\
\hline Position skill work & $\begin{array}{l}\text { Athletes separate into skill groups (i.e., line \& skill or } \\
\text { offense \& defense) }\end{array}$ & Practice offensive- or defensive-specific skills \& game strategy \\
\hline Scrimmage & Interteam scrimmage (i.e., w/ another team) & $\begin{array}{l}\text { Practice of offense \& defense game strategy in a gamelike situation } \\
\text { btwn adjacent age- \& weight-classified teams }\end{array}$ \\
\hline Special teams & $\begin{array}{l}\text { Players practice kickoff, kickoff return, punt, \& punt } \\
\text { return plays }\end{array}$ & $\begin{array}{l}\text { Practice alignment \& responsibilities for different special-teams } \\
\text { scenarios }\end{array}$ \\
\hline Tackling drill stations & $\begin{array}{l}\text { Team is separated into smaller groups that complete a } \\
\text { series of tackling/blocking drills }\end{array}$ & $\begin{array}{l}\text { Practice tackling \& blocking drills in smaller groups w/ a higher coach- } \\
\text { to-player ratio than in whole-team tackling drills }\end{array}$ \\
\hline Technique drill & $\begin{array}{l}\text { Athletes practice tackling/blocking at a "walk-through" } \\
\text { pace w/ limited to no contact }\end{array}$ & Learn correct form \& technique for tackling/blocking \\
\hline
\end{tabular}

Illustrations of drill setups for several drills are shown in Appendix Fig. A1.

* Excluded from statistical analyses due to small sample size and variations in the drill that limited meaningful comparisons.

† Study members were present at practice and noted drill setup. The closing distance was also confirmed in video review of the drill.

the drill setup. Impacts occurring while the athletes were not helmeted were excluded from the data set. Using the drill start and stop times from the video data, each head impact was paired to a specific drill. The practice drills were classified as: dummy/sled tackling, half install, install, install walk through, multiplayer tackle, Oklahoma, one-on-one, open field tackling, passing, position skill work, scrimmage, special teams, tackling drill stations, and technique (Table 2 and Appendix Figure A1).

HIE was quantified in terms of impact rate and mean, median, and 95th percentile head acceleration. The impact rate for each drill was described as the impacts per player per minute (ppm). Generalized linear models were fitted, and Wald tests were used to assess differences in the impact rate and head accelerations among drills. ${ }^{27}$ The models were adjusted for the confounding factors of impact date and team. Generalized linear models were also used to evaluate the effect of team on the impact rate and head accelerations within the drills with the highest number of impacts: install, position skill work, one-on-one, Oklahoma, and open field tackling. For inference, log transformations were applied for all analyses due to the right-skewed distribution of the data. A Bonferroni correction was applied for all statistical tests to identify significant pairwise differences while controlling the overall alpha level to be
0.05. All models controlled for multiple impacts from the same athlete. All statistical analyses were performed using SAS software version 9.4 (SAS Institute Inc.). Lastly, 4 simplified drill classifications based on the nature of player contact were created (Table 3 ). The resulting distribution of time spent on these drills relative to the number of head impacts and overall HIE was compared among teams.

\section{Results}

A total of 15,443 impacts were collected in practices over 2 seasons from 56 individual athletes. Eleven of the athletes participated in the study for both years, totaling 67 athlete-seasons (Table 4). There were 263 impacts that occurred during 20 helmet-only (i.e., noncontact) practices, which were excluded from this analysis. An additional 462 impacts that occurred during conditioning (119) or an unknown (343) drill were also excluded. This resulted in 14,718 impacts included in the final data set for analysis in the present study. The median/95th percentile linear and rotational accelerations of all contact practice head impacts were 19.0/50.0 g and 936.2/2368.9 $\mathrm{rad} / \mathrm{sec}^{2}$, respectively. The total number of head impacts in contact practices for each athlete throughout a season ranged from 32 to 781 with a median of 185 impacts. 



FIG. 1. Mean values and $95 \%$ confidence intervals (Cls) for resultant linear acceleration (A), resultant rotational acceleration (B), and impact rate $(\mathbf{C})$ for each drill. Significant differences in acceleration and impact rate are indicated by nonoverlapping $95 \% \mathrm{Cls}$.

\section{Comparison of HIE Among Drills}

Among all 6 teams, there were significant differences in HIE among the practice drills. The mean linear $(\mathrm{p}<$ $0.0001)$ and rotational $(\mathrm{p}<0.0001)$ acceleration varied significantly among all drills (Fig. 1A and B). Open field tackling had the highest mean linear acceleration, which was significantly greater than all other drills $(\mathrm{p}<0.001)$. Oklahoma had a mean linear acceleration significantly greater than several other drills $(\mathrm{p}<0.05)$, and one-onone had significantly greater mean linear acceleration than the technique drill $(\mathrm{p}<0.05)$. Open field tackling also had the highest mean rotational acceleration. The impact rate varied significantly $(\mathrm{p}<0.0001)$ among the drills (Fig. 1C). Multiplayer tackle had the highest mean impact rate, followed by one-on-one, tackling drill stations, and then Oklahoma. Regarding the total number of impacts for each drill, install had the highest number of impacts $(n=7791)$, and the drills with the lowest number of impacts were technique $(n=37)$ and passing $(n=51)$. It is important to note that some drills were not practiced by every team, so Appendix Table A1 lists which teams practiced each drill and provides a full summary of descriptive statistics.

\section{Comparisons of HIE Among Teams Within Drills}

Differences in HIE among the 6 teams (A-F) were evaluated for the drills with the highest number of head impacts: install, Oklahoma, one-on-one, open field tackling, and position skill work. A complete summary of mean (95\% CI) linear acceleration, rotational acceleration, and impact rate for each team is shown in Appendix Table A2. Mean linear acceleration varied significantly among teams in the install, one-on-one, and open field tackling drills, but there were no significant differences in mean rotational acceleration (Table 5). Team A had the highest mean (95\% CI) linear acceleration among all teams for these 3 drills: $21.3 g(20.2 g, 22.5 g), 23.9 g(20.8 g, 27.4 g)$, and $28.6 g$ (23.9g, $34.2 g$ ), respectively. Team $\mathrm{E}$ had the lowest mean linear acceleration in install $(19.0 \mathrm{~g}[17.9 \mathrm{~g}, 20.1 \mathrm{~g}])$ and one-on-one 
TABLE 3. Summary of drills categorized into 4 simplified classifications based on type of player contact

\begin{tabular}{ll}
\hline \multicolumn{1}{c}{ Drill Classification } & \multicolumn{1}{c}{ Drill Name } \\
\hline \multirow{3}{*}{ Minimal or no player vs player contact } & \multicolumn{1}{c}{ Dummy/sled tackling } \\
\cline { 2 - 2 } & Half install \\
\cline { 2 - 2 } & Install walk through \\
\cline { 2 - 2 } & Passing \\
\hline \multirow{3}{*}{ Multiple players vs player(s) contact } & Technique drill \\
& Install \\
\hline & Multiplayer tackle \\
\cline { 2 - 2 } & Oklahoma \\
\hline \multirow{3}{*}{ Other (contact varied) } & Scrimmage \\
\hline \multirow{2}{*}{ Single player vs player contact } & Tackling drill stations \\
\hline & Other \\
\hline & Position skill work \\
\hline & Special teams \\
\hline
\end{tabular}

(18.1 $g[17.2 g, 19.0 g])$. Team D had the lowest mean linear acceleration in open field tackling $(22.2 g[18.7 g, 26.4 g])$. The impact rate varied significantly among teams in the Oklahoma and position skill work drills (Table 5). Team A had the highest mean impact rate for Oklahoma $(0.38 \mathrm{ppm}$ [0.31 ppm, $0.46 \mathrm{ppm}])$ and position skill work $(0.11 \mathrm{ppm}$ [0.08 ppm, $0.15 \mathrm{ppm}])$. Team $\mathrm{C}$ had the lowest impact rate in Oklahoma (0.16 ppm [0.12 ppm, $0.22 \mathrm{ppm}]$ ) and position skill work (0.06 ppm [0.04 ppm, 0.08 ppm]).

\section{Comparison of Practice Structure Among Teams}

The practice structure and amount of time spent on each simplified drill classification varied among teams, but there were some similarities (Fig. 2). Of the time spent on known drills in practice, teams A, C, D, and E spent the largest percentage of time on multiple players versus player(s) contact drills, whereas teams B and F spent the largest percentage of time on other (contact varied) drills. Team E spent $12 \%$ of their time on single-player versus player contact drills, which was the highest compared to all other teams. Despite team A spending the greatest percentage of time on minimal- or no-player versus player contact drills (27\%) compared to all other teams, they had the highest median and 95th percentile linear acceleration and the second highest median and 95th percentile impacts per player per practice.
TABLE 5. Summary of $p$ values resulting from generalized linear models testing the effect of team on linear acceleration, rotational acceleration, and impact rate within drills with the highest number of head impacts

\begin{tabular}{|c|c|c|c|}
\hline \multirow[b]{2}{*}{ Drill } & \multicolumn{3}{|c|}{$p$ Value } \\
\hline & $\begin{array}{c}\text { Linear } \\
\text { Acceleration }\end{array}$ & $\begin{array}{l}\text { Rotational } \\
\text { Acceleration }\end{array}$ & $\begin{array}{c}\text { Impact } \\
\text { Rate }\end{array}$ \\
\hline Install & 0.04 & 0.5 & 0.1 \\
\hline Oklahoma & 0.2 & 0.6 & $<0.0001$ \\
\hline One-on-one & 0.0005 & 0.1 & 0.3 \\
\hline Open field tackling & 0.02 & 0.1 & 0.1 \\
\hline Position skill work & 0.07 & 0.3 & 0.01 \\
\hline
\end{tabular}

\section{Discussion}

This study evaluated HIE among football practice drills across 6 age- and weight-restricted youth teams. Prior studies have found that HIE significantly varies among practice drills, with full-speed tackling drills resulting in the highest head accelerations, and tackling or blocking drills with multiple player involvement resulting in the highest impact frequency. ${ }^{10,21}$ Although these studies have provided insight into HIE in youth football practices, they were limited in size and did not account for variability among teams, which is an important factor since HIE can vary significantly among teams with the same age and weight restrictions..$^{22}$ The present study supports the results from prior investigations and determined that team has an effect on HIE in practice.

Open field tackling had the highest mean linear and rotational acceleration compared to all other drills evaluated in this study, which further supports a previous study that also found open field tackling to have the highest head accelerations. ${ }^{21}$ A study of high-magnitude head impacts in youth football practices and games found that high-magnitude impacts ( $>40 g$ ) occur most frequently in the open field in both games $(59.4 \%)$ and practices $(67.5 \%) .{ }^{9}$ However, teams only practiced open field tackling 1-4 times in a season, with the exception of team E, which practiced this drill 12 times. Despite players on all teams consistently tackling to the ground, there were significant variations in mean linear acceleration among teams. Team D, which had the lowest linear acceleration, only set up the drill with a closing distance of 4-6 yards, whereas the other teams typically had a larger closing distance of 5-10 yards. Team $\mathrm{A}$, which had the highest mean linear acceleration in this drill, consistently had a closing distance of $>6$ yards. Al-

TABLE 4. Summary of demographics data for all athletes and stratified by team

\begin{tabular}{crrrrrrc}
\hline & \multicolumn{7}{c}{ Team $($ mean \pm SD) } \\
\cline { 2 - 8 } Variable & \multicolumn{1}{c}{ A } & \multicolumn{1}{c}{ B } & \multicolumn{1}{c}{ C } & D & E & F & All Teams \\
\hline Age $(\mathrm{yrs})$ & $11.2 \pm 0.6$ & $11.4 \pm 0.4$ & $12.3 \pm 0.6$ & $12.3 \pm 0.5$ & $12.9 \pm 0.6$ & $13.2 \pm 0.5$ & $12.2 \pm 0.9$ \\
\hline Height $(\mathrm{cm})$ & $151.5 \pm 5.5$ & $148.0 \pm 5.4$ & $149.3 \pm 5.3$ & $158.6 \pm 7.1$ & $160.8 \pm 8.9$ & $165.2 \pm 5.9$ & $155.6 \pm 8.8$ \\
\hline Weight $(\mathrm{kg})$ & $44.9 \pm 4.1$ & $42.4 \pm 7.4$ & $43.5 \pm 6.9$ & $52.1 \pm 4.4$ & $58.1 \pm 11.8$ & $61.8 \pm 8.4$ & $50.4 \pm 10.0$ \\
\hline BMl $\left(\mathrm{kg} / \mathrm{m}^{2}\right)$ & $19.3 \pm 3.1$ & $19.8 \pm 3.1$ & $19.9 \pm 2.3$ & $21.3 \pm 2.7$ & $23.0 \pm 4.3$ & $23.1 \pm 2.9$ & $21.0 \pm 3.2$ \\
\hline
\end{tabular}




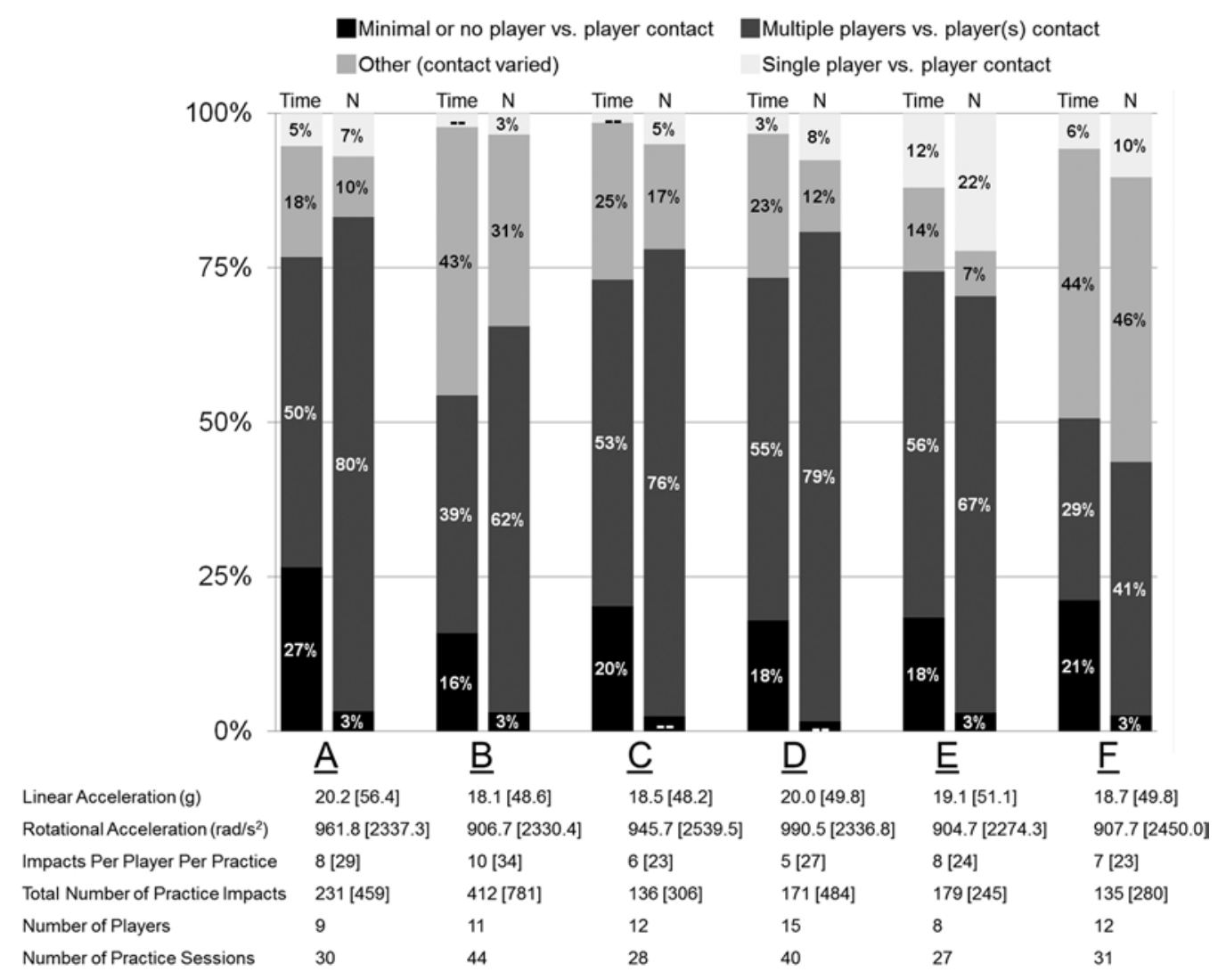

FIG. 2. Distribution of time spent and number of impacts measured in the simplified drill classifications for each team. Median and 95th percentile values are shown for linear acceleration, rotational acceleration, total number of practice impacts per player, and impacts per player per practice. The dashed line (--) indicates $<3 \%$.

though increased closing distance has been associated with increased head impact severity, ${ }^{34}$ team B also consistently had a closing distance of $>6$ yards but a comparably lower mean linear acceleration $(23.6 \mathrm{~g}[21.8 \mathrm{~g}, 25.6 \mathrm{~g}])$. The time spent on instruction was not quantified in this study, but team B seemed to spend more time demonstrating and correcting tackling technique throughout the drill. This team also seemed to tackle with lower speed in open field tackling, and although speed was not measured in the present analysis, it should be considered in future studies. Open field tackles do occur in games and it may be important to introduce those scenarios in practices to prepare players; however, reducing closing distance to $<6$ yards, lowering player speed, and emphasizing correct tackling technique may help reduce head impact severity.

Linear acceleration also varied significantly among teams within install and one-on-one drills. Despite all teams organizing and running these drills comparably, team A consistently had the highest head impact severity among all teams. This may partially be due to team A's high intensity while engaging in contact. Although a measure of intensity was not quantified in this study, the athletes on team A typically had higher energy and speed while engaging in contact during install and often tackled players to the ground. In contrast, the players on team E, which had the lowest linear acceleration in install, would tackle and block with lower speed, with contact frequently stopped before the ball carrier was tackled to the ground.
Team E would also typically limit contact initially and then progress to full contact. Similarly, in one-on-one, players on team $\mathrm{E}$ were more likely to engage in contact at a lower speed than team A and stop contact before completing the tackle. A recent study evaluating mechanisms of concussive impacts in youth football found that of concussions that occurred in practice, the largest proportion (37.9\%) were due to being tackled. ${ }^{28}$ Another study that compared tackling technique proficiency between injurious and non-injurious tackles in youth rugby found that higher criterion-specific tackle technique scores were associated with non-injurious outcome. ${ }^{8}$ They also found that injury was less likely when tacklers reduced speed and shortened their steps prior to contact. ${ }^{8}$ Further investigation into differences in head impact severity among tackling techniques in football and the associated head impact mechanism is warranted to better understand how HIE can be reduced. Stopping contact between players before the tackle is completed and lowering the intensity of contact (e.g., reducing player speed) may mitigate head accelerations.

Impact rate varied significantly among practice drills and multiplayer tackle had the highest impact rate. Despite install requiring the majority of the team to participate in player-to-player contact, this drill had a significantly lower impact rate than several other drills. This may partially be due to the amount of time spent on instructing the teams about game strategy, positioning, and so on. ${ }^{21}$ In contrast, drills primarily focused on tackling and blocking, such as 
Oklahoma, had higher impact rates and only had instruction at the beginning and during brief intermittent pauses to correct technique. These results suggest that time spent on instruction and correcting technique may affect impact rate. However, the impact rate metric in this study includes time spent on instruction and practicing the drills, but it did not quantify each separately. Future studies should consider the effect of time spent on instruction compared to time spent engaged in contact on HIE. The impact rate also varied significantly among teams within the Oklahoma drill. Although all teams ran the Oklahoma drill comparably, there were variations in the number of blockers/tacklers and the specific setup of players within the drill (Appendix Fig. A1). Team A, which had the highest impact rate for Oklahoma, conducted the drill 5 times and typically had 6 or 7 players participate in the drill. In contrast, team $\mathrm{C}$, which had the lowest impact rate, also ran Oklahoma 5 times, but only had more than 4 players participate during 2 sessions; the other days, only 3 or 4 players participated at a time. Reducing the number of active participants in fullspeed contact drills may help reduce impact rate. Overall, drills that primarily focused on full-speed tackling and blocking scenarios resulted in the highest impact rates.

All teams structured their practice schedule differently, which may affect their overall HIE in practice. Team $\mathrm{E}$ spent the highest percentage of time on single-player versus player contact drills (Fig. 2) compared to the other teams, which may have contributed to their high 95th percentile linear acceleration $(51.1 \mathrm{~g})$. However, team A spent the greatest percentage of time on minimal- or no-contact drills, but they had the highest 50th and 95th percentile linear acceleration in practice. Additionally, despite having the youngest and lightest age and weight restrictions, which is associated with lower HIE, ${ }^{22}$ the athletes on team A had the highest mean linear acceleration and impact rate among teams in several drills. These results suggest that spending less time on contact drills does not ensure lower head impact magnitude or frequency in practices. ${ }^{22}$ A study of youth ice hockey players by Schmidt et al. that used the Competitive Aggressiveness and Anger Scale and the HIT System found that less aggressive adolescent boys sustained less severe head impacts than more aggressive adolescent boys in practices. ${ }^{36}$ Behavioral tendencies, such as increased aggression, coaching style, tackling technique, and practicing with higher intensity (e.g., higher speed of players engaged in contact) may have played a role in team A's increased HIE. Studies have shown that restrictions to the amount of contact in football practice can reduce the number of impacts, but impact magnitude may not be affected. ${ }^{6,12} \mathrm{HIE}$ in practice may be more influenced by the individual athletes and how drills are taught and run rather than the amount of time spent on each type of drill. Solely reducing time spent on contact drills may not lower overall HIE.

\section{Limitations}

There were some limitations in this study that should be noted. The results from this study suggest that HIE in practice is not solely dependent on the types of practice drills and amount of contact time but is likely also influenced by individual athletes and how drills are taught and run. However, additional factors that were not explored in this study, such as tackling technique, may have contributed to differences in HIE. Further study of factors that may affect HIE in practice is warranted. The teams included in this study were limited to a single organization and league, which have rules and regulations for practice that may differ from teams associated with other organizations. However, this study does account for 3 separate age- and weight-restricted levels of play across 2 seasons, and all teams are part of one of the largest national youth football organizations. Further study of HIE in drills among more youth football teams from other organizations and regions, as well as high school and college athletes, would also benefit our understanding of HIE in practice. There were 462 impacts excluded in the present study because they occurred during conditioning or unknown drills; however, this represents less than $3 \%$ of the total impacts collected from this sample. The impact rate metric, impacts per minute per player, only includes measured impacts; it does not account for instances of participation in the drill and no measured impacts. We did not instrument every player on each team or control for position; however, we instrumented $50 \%$ or greater of every team and players from a variety of positions. Athletes also typically played multiple positions. There were no clinically diagnosed concussions in study participants during practices, so the results lack correlation to injury outcome; however, the outcome variable in this analysis is HIE, which can be used to inform rule changes to reduce exposure to repetitive head impacts. ${ }^{6} 12$ Lastly, the HIT System has some error associated with individual impact acceleration measurements. However, the error of acceleration measurements is within the range of acceptable error for other measurement devices. ${ }^{4}$ Additionally, distributions of data, rather than individual data points, were evaluated in this study to mitigate the effects of random error.

\section{Conclusions}

Full-speed tackling and blocking drills resulted in the highest HIE among all teams included in this study. However, mean linear acceleration and impact rate varied significantly among teams within several drills. Age and weight (i.e., level of play) did not account for all differences in HIE between teams. Findings suggest reducing the intensity of player-to-player contact in practice and improving tackling technique may reduce HIE more effectively than broad reductions in time spent on player contact drills. The results of this study contribute the body of work informing evidence-based recommendations to improve head impact safety in youth football. Further evaluation of tackling/blocking techniques that reduce HIE and the role of coach instruction is warranted to improve our understanding of individual, team, and coach influences on HIE in football.

\section{Acknowledgments}

Research reported in this publication was supported by the National Institute of Neurological Disorders and Stroke of the National Institutes of Health (NIH) under award nos. R01NS094410 and R01NS082453. The National Center for 
Advancing Translational Sciences, NIH, through grant no. KL2TR001421 supported Dr. Urban. The content is solely the responsibility of the authors and does not necessarily represent the official views of the NIH.

We give special thanks to the Childress Institute for Pediatric Trauma at Wake Forest Baptist Medical Center for providing support for this study. We also thank the youth football league's coordinators, coaches, parents, athletes, and athletic trainer whose support made this study possible. We also thank Danielle Rocheleau, Joeline Kane, Katie Fabian, Ana Katsafanas, Megan Anderson, Leslie Hoyt, Megan Rosenberg, Kate Middleton, Kat Beck, and Alexander Lord for their valuable assistance in this research.

\section{References}

1. Aspen Institute: Project Play Survey of Parents on Youth Sports Issues. (https://staticl.squarespace.com/ static/595ea7d6e58c62dce01d1625/t/5a58fbf 824a6942cc4f5 3e35/1515781124206/espnw-Aspen+Institute+Project+Play+ Survey+of+Parents+on+youth+sports+issues.pdf) [Accessed October 12, 2018]

2. Bahrami N, Sharma D, Rosenthal S, Davenport EM, Urban JE, Wagner B, et al: Subconcussive head impact exposure and white matter tract changes over a single season of youth football. Radiology 281:919-926, 2016

3. Beachy G, Rauh M: Middle school injuries: a 20-year (19882008) multisport evaluation. J Athl Train 49:493-506, 2014

4. Beckwith JG, Greenwald RM, Chu JJ: Measuring head kinematics in football: correlation between the head impact telemetry system and Hybrid III headform. Ann Biomed Eng 40:237-248, 2012

5. Broglio SP, Sosnoff JJ, Shin S, He X, Alcaraz C, Zimmerman J: Head impacts during high school football: a biomechanical assessment. J Athl Train 44:342-349, 2009

6. Broglio SP, Williams RM, O'Connor KL, Goldstick J: Football players' head-impact exposure after limiting of fullcontact practices. J Athl Train 51:511-518, 2016

7. Bryan MA, Rowhani-Rahbar A, Comstock RD, Rivara F: Sports- and recreation-related concussions in US youth. Pediatrics 138: 138, 2016

8. Burger N, Lambert MI, Viljoen W, Brown JC, Readhead C, Hendricks S: Tackle technique and tackle-related injuries in high-level South African Rugby Union under-18 players: realmatch video analysis. Br J Sports Med 50:932-938, 2016

9. Campolettano ET, Gellner RA, Rowson S: High-magnitude head impact exposure in youth football. J Neurosurg Pediatr 20:604-612, 2017

10. Campolettano ET, Rowson S, Duma SM: Drill-specific head impact exposure in youth football practice. J Neurosurg Pediatr 18:536-541, 2016

11. Chao S, Pacella MJ, Torg JS: The pathomechanics, pathophysiology and prevention of cervical spinal cord and brachial plexus injuries in athletics. Sports Med 40:59-75, 2010

12. Cobb BR, Urban JE, Davenport EM, Rowson S, Duma SM, Maldjian JA, et al: Head impact exposure in youth football: elementary school ages 9-12 years and the effect of practice structure. Ann Biomed Eng 41:2463-2473, 2013

13. Crisco JJ, Chu JJ, Greenwald RM: An algorithm for estimating acceleration magnitude and impact location using multiple nonorthogonal single-axis accelerometers. J Biomech Eng 126:849-854, 2004

14. Crisco JJ, Wilcox BJ, Beckwith JG, Chu JJ, Duhaime AC, Rowson S, et al: Head impact exposure in collegiate football players. J Biomech 44:2673-2678, 2011

15. Daniel RW, Rowson S, Duma SM: Head impact exposure in youth football. Ann Biomed Eng 40:976-981, 2012

16. Davenport EM, Apkarian K, Whitlow CT, Urban JE, Jensen $\mathrm{JH}$, Szuch E, et al: Abnormalities in diffusional kurtosis metrics related to head impact exposure in a season of high school varsity football. J Neurotrauma 33:2133-2146, 2016

17. Eime RM, Young JA, Harvey JT, Charity MJ, Payne WR: A systematic review of the psychological and social benefits of participation in sport for children and adolescents: informing development of a conceptual model of health through sport. Int J Behav Nutr Phys Act 10:98, 2013

18. Funk JR, Rowson S, Daniel RW, Duma SM: Validation of concussion risk curves for collegiate football players derived from HITS data. Ann Biomed Eng 40:79-89, 2012

19. Hendricks S, O'connor S, Lambert M, Brown J, Burger N, Mc Fie S, et al: Contact technique and concussions in the South African under-18 Coca-Cola Craven Week Rugby tournament. Eur J Sport Sci 15:557-564, 2015

20. Jewett R, Sabiston CM, Brunet J, O'Loughlin EK, Scarapicchia T, O'Loughlin J: School sport participation during adolescence and mental health in early adulthood. J Adolesc Health 55:640-644, 2014

21. Kelley ME, Kane JM, Espeland MA, Miller LE, Powers AK, Stitzel JD, et al: Head impact exposure measured in a single youth football team during practice drills. J Neurosurg Pediatr 20:489-497, 2017

22. Kelley ME, Urban JE, Miller LE, Jones DA, Espeland MA, Davenport EM, et al: Head impact exposure in youth football: comparing age- and weight-based levels of play. J Neurotrauma 34:1939-1947, 2017

23. Kerr ZY, Marshall SW, Simon JE, Hayden R, Snook EM, Dodge T, et al: Injury rates in age-only versus age-and-weight playing standard conditions in American youth football. Orthop J Sports Med 3:2325967115603979, 2015

24. Kerr ZY, Yeargin S, Valovich McLeod TC, Nittoli VC, Mensch J, Dodge T, et al: Comprehensive coach education and practice contact restriction guidelines result in lower injury rates in youth American football. Orthop J Sports Med 3:2325967115594578, 2015

25. Kerr ZY, Yeargin SW, Valovich McLeod TC, Mensch J, Hayden R, Dompier TP: Comprehensive coach education reduces head impact exposure in American youth football. Orthop J Sports Med 3:2325967115610545, 2015

26. Kroshus E, Kerr ZY, Lee JGL: Community-level inequalities in concussion education of youth football coaches. Am J Prev Med 52:476-482, 2017

27. Littell RC, Milliken GA, Stroup WW, Wolfinger RD: SAS System for Mixed Models. Cary, NC: SAS Institute Inc, 1996

28. Lynall RC, Campbell KR, Wasserman EB, Dompier TP, Kerr ZY: Concussion mechanisms and activities in youth, high school, and college football. J Neurotrauma 34:2684-2690, 2017

29. Manoogian S, McNeely D, Duma S, Brolinson G, Greenwald $\mathrm{R}$ : Head acceleration is less than 10 percent of helmet acceleration in football impacts. Biomed Sci Instrum 42:383388, 2006

30. McAllister TW, Ford JC, Flashman LA, Maerlender A, Greenwald RM, Beckwith JG, et al: Effect of head impacts on diffusivity measures in a cohort of collegiate contact sport athletes. Neurology 82:63-69, 2014

31. Montenigro PH, Alosco ML, Martin BM, Daneshvar DH, Mez J, Chaisson CE, et al: Cumulative head impact exposure predicts later-life depression, apathy, executive dysfunction, and cognitive impairment in former high school and college football players. J Neurotrauma 34:328-340, 2017

32. Montenigro PH, Bernick C, Cantu RC: Clinical features of repetitive traumatic brain injury and chronic traumatic encephalopathy. Brain Pathol 25:304-317, 2015

33. Munce TA, Dorman JC, Thompson PA, Valentine VD, Bergeron MF: Head impact exposure and neurologic function of youth football players. Med Sci Sports Exerc 47:15671576,2015 
34. Ocwieja KE, Mihalik JP, Marshall SW, Schmidt JD, Trulock SC, Guskiewicz KM: The effect of play type and collision closing distance on head impact biomechanics. Ann Biomed Eng 40:90-96, 2012

35. Pfister T, Pfister K, Hagel B, Ghali WA, Ronksley PE: The incidence of concussion in youth sports: a systematic review and meta-analysis. Br J Sports Med 50:292-297, 2016

36. Schmidt JD, Pierce AF, Guskiewicz KM, Register-Mihalik JK, Pamukoff DN, Mihalik JP: Safe-play knowledge, aggression, and head-impact biomechanics in adolescent ice hockey players. J Athl Train 51:366-372, 2016

37. Solomon GS, Kuhn AW, Zuckerman SL, Casson IR, Viano DC, Lovell MR, et al: Participation in pre-high school football and neurological, neuroradiological, and neuropsychological findings in later life: a study of 45 retired National Football League players. Am J Sports Med 44:1106-1115, 2016

38. Stamm JM, Bourlas AP, Baugh CM, Fritts NG, Daneshvar $\mathrm{DH}$, Martin BM, et al: Age of first exposure to football and later-life cognitive impairment in former NFL players. Neurology 84:1114-1120, 2015

39. Swartz EE, Broglio SP, Cook SB, Cantu RC, Ferrara MS, Guskiewicz KM, et al: Early results of a helmetless-tackling intervention to decrease head impacts in football players. J Athl Train 50:1219-1222, 2015

40. Tagge CA, Fisher AM, Minaeva OV, Gaudreau-Balderrama A, Moncaster JA, Zhang XL, et al: Concussion, microvascular injury, and early tauopathy in young athletes after impact head injury and an impact concussion mouse model. Brain 141:422-458, 2018

41. Talavage TM, Nauman EA, Breedlove EL, Yoruk U, Dye AE, Morigaki KE, et al: Functionally-detected cognitive impairment in high school football players without clinicallydiagnosed concussion. J Neurotrauma 31:327-338, 2014

42. Trofa DP, Park CN, Noticewala MS, Lynch TS, Ahmad CS, Popkin CA: The impact of body checking on youth ice hockey injuries. Orthop J Sports Med 5:2325967117741647, 2017

43. Urban JE, Davenport EM, Golman AJ, Maldjian JA, Whitlow CT, Powers AK, et al: Head impact exposure in youth foot- ball: high school ages 14 to 18 years and cumulative impact analysis. Ann Biomed Eng 41:2474-2487, 2013

44. US Department of Health and Human Services: Physical Activity Guidelines Advisory Committee Report. Washington, DC: US Department of Health and Human Services, 2008 (https://health.gov/paguidelines/report/) [Accessed October 11, 2018]

\section{Disclosures}

The authors report no conflict of interest concerning the materials or methods used in this study or the findings specified in this paper.

\section{Author Contributions}

Conception and design: Urban, Kelley. Acquisition of data: Kelley, Flood. Analysis and interpretation of data: Urban, Kelley, Espeland, Flood. Drafting the article: Urban, Kelley. Critically revising the article: Urban, Kelley, Whitlow, Stitzel. Reviewed submitted version of manuscript: Urban, Kelley, Espeland, Flood, Whitlow, Maldjian, Stitzel. Statistical analysis: Kelley, Espeland. Administrative/technical/material support: Urban, Powers, Whitlow, Maldjian, Stitzel. Study supervision: Urban, Kelley, Whitlow, Maldjian, Stitzel.

\section{Supplemental Information Online-Only Content}

Supplemental material is available with the online version of the article.

Appendix. https://thejns.org/doi/suppl/10.3171/2018.9. PEDS18314.

\section{Correspondence}

Jillian E. Urban: Virginia Tech-Wake Forest University School of Biomedical Engineering and Sciences, Winston-Salem, NC. jurban@wakehealth.edu. 